\title{
Joint preservation after hip arthroscopy in patients with FAl. Prospective analysis with a minimum follow-up of seven years
}

\author{
Fernando Comba \\ Carlos Yacuzzi \\ Pablo J. Ali \\ Gerardo Zanotti \\ Martin Buttaro \\ Francisco Piccaluga
}

Hip Surgery Unit, Institute of Orthopaedics

"Carlos E. Ottolenghi",

Hospital Italiano de Buenos Aires, Argentina

\author{
Corresponding author: \\ Fernando Comba \\ Hip Surgery Unit \\ Institute of Orthopaedics "Carlos E. Ottolenghi", \\ Hospital Italiano de Buenos Aires \\ 4247 Potosí St. PC: 1199 ACK - Buenos Aires, \\ Argentina \\ Phone/Fax: (54-11) 4959-0200 ext. 8314 \\ E-mail: fernando.comba@hospitalitaliano.org.ar
}

\section{Summary}

Background: The purpose of this study is to evaluate the clinical outcomes, radiological degenerative progression and the joint preservation rate in a series of patients with Femoroacetabular Impingement (FAl) treated with hip arthroscopy at a minimum follow-up of 7 years. The predictive factors for total hip arthroplasty (THA) requirement were analyzed.

Materials and methods: Between February 2008 and February 2009, 42 consecutive patients treated with hip arthroscopy due to FAl syndrome were included. There were 15 women and 27 men with an average age of 38 years (range 23 to 56 years). The surgery involved joint damage stabilization (labral tears and/or chondrolabral injuries) and correction of associated bony deformities (cam and/or pincer lesions). A prospective clinical follow-up was made with no patient lost. We specifically addressed the need for THA. Predictive factors for THA were also analyzed.

Results: At final follow up, joint preservation rate was $83.33 \%$ (Cl 95\% 68,64\%-93,03\%). Probability of evolving to a THA in patients with radiographic preoperative Tonnis grades 0 and I was of $0 \%(\mathrm{CI}$ 95\%: 0-12.77). Probability of evolving to a THA in patients with preoperative Tonnis grades II and III was $46,67 \%$ (Cl 95\%21.27\%-73,41\%). A statistically significant difference was present between both groups $(p=0.002)$. Patients older than 45 years at the time of hip arthroscopy were at significant risk of evolving to a THA $(p=0.0012)$. Excluding those patients who undergone a THA: modified HHS was 88.25 points $(80-96)$ and radiographic analysis addressed a $14,29 \%$ (IC95\% $4,81 \%-30,26 \%$ ) of progressive degenerative changes without affecting clinical results.

Conclusions: Hip arthroscopy for the treatment of patients with FAl syndrome showed favorable results regarding joint preservation. Patients with preoperative radiographic evidence of advanced-stage osteoarthritis and those older than $\mathbf{4 5}$ years at the time of surgery have higher risk of requiring THA.

Level of evidence: IV.

KEY WORDS: femoroacetabular impingement, hip arthroscopy, labral tears, hip osteoarthritis.

\section{Introduction}

Femoroacetabular impingement (FAI) syndrome is one of the most frequent causes of hip pain in the young adult ${ }^{1}$. It is defined on the basis of pathoanatomic features, as an abnormal contact between the proximal femur and the acetabular rim1. This mechanical condition results to a progressive acetabular labral and chondral injury and potentially, a cascade of events leading to hip arthritis ${ }^{2}$.

Several studies have shown the association between FAl syndrome and the development of early degenerative changes which lead to hip arthritis in young adult ${ }^{3,4}$. This association strengthens the importance of its treatment, since controlling the mechanical conflict might result in a delay in the development of hip osteoarthritis ${ }^{5}$.

Good results have been described with an open procedure and with hip arthroscopy for the treatment of FAl. Aims of the surgery are to recover function, relieve pain and restore joint mechanics ${ }^{5}$. However, the results of such treatment are described with short or mid-term follow-up periods, being the outcome assessment focused on the clinical aspect. Reports describing radiological progression and defining joint preservation rate are rare ${ }^{5,6}$.

The objective of the present study was to evaluate clinical outcomes, radiological degenerative progres- 
sion and joint preservation rate in patients who underwent hip arthroscopy due to femoroacetabular impingement (FAI) syndrome. The predictive factors required for total hip arthroplasty (THA) were also analyzed during this period.

This article submits to the ethical standards of the journal ${ }^{7}$.

\section{Materials and Methods}

Between May 2007 and March 2016, 556 hip arthroscopies were performed in one single institution and by only one surgeon. Inclusion criteria involved those patients who underwent hip arthroscopy with a diagnosis of FAl syndrome, and with a minimum 7-year follow-up. Therefore, arthroscopies for other diagnoses and cases with a shorter follow-up were excluded. Besides, the first 30 cases addressed with this technique during the first year of experience were also excluded since, according to current criteria, this number of patients might be related to the so-called training curve, and be associated to a higher rate of complications and poor results ${ }^{8}$.

The period of study, then, includes a consecutive series of patients, between February 2008 and February 2009, who underwent hip arthroscopy for FAI syndrome. The series involved 42 patients (15 female, 27 male) with a mean age of 38 years (range 23 to 56 years). The indication of hip arthroscopy was, in all cases, pain to perform daily and/or sport activities, with a failure of conservative therapeutic measures, and positive findings on the imaging studies. All patients were studied with Antero-Posterior pelvic Xrays, with a distance under $1.5 \mathrm{~cm}$ between pubic symphysis and coccyx. In this way, we could identify acetabulum retroversion when the anterior acetabular wall crossed over the posterior acetabular wall (presence of the "cross-over sign"). We also could measure the presence of a "coxa profunda", by measuring the relation between the femoral head and ilioischial line, or center of rotation, with the posterior wall ${ }^{2}$. These last two signs indicate a Pincer type FAI. Alpha angle was measured on lateral X-rays ${ }^{9}$. A value above 50 grades is indicative of a Cam-type lesion ${ }^{9}$. Simple X-rays were also used to define the grade of arthrosis according the radiologic classifications described by Tonnis ${ }^{10}$. Table I summarizes patients' epidemiology and data analyzed.

\section{Surgical technique}

In all cases, hip arthroscopy was performed with the patient in the supine position and on a fracture table, under combined anesthesia (epidural anesthesia plus neuroleptoanalgesia). Traction was performed, according to Byrd's description ${ }^{11}$, with a padded and wide perineal post to displace the hip laterally and, in this way, optimize traction force and prevent complications. First, arthroscopy of the central compartment was performed through an anterolateral portal placed with radioscopic guide, and the mid-anterior portal placed under direct arthroscopic vision. The central compartment can only be explored under traction, it is laterally limited by the acetabular rim and includes: the femoral head, acetabular fossa, ligamentum Teres, acetabular cartilage surface and the labrum. Labral or chondrolabral junction lesions were treated with arthroscopic techniques (debridement with a shaver and radiofrequency for flaps or unstable lesions). At this stage of surgery, pincer-like lesions were also corrected with a motorized burr. It is worth highlighting that during the period of study, we still not perform labral repair with anchors as we routinely do at the present. Labral lesions were documented and cartilage lesions classified according to Outerbridge classification ${ }^{12}$. Advanced grade chondral lesions with subchondral bone exposure were treated by microfractures. Figure 1 describes the different types of chondral lesions. Then, without traction and with the addition of a proximal accessory third portal, arthroscopic exploration of the peripheral compartment was performed, which is the anterior and lateral portion of the intracapsular femoral neck. The proximal accessory portal is introduced with radioscopic guidance and under direct vision. The soft parts of the anterior face of the neck are treated with shaver and radiofrequency, delimiting the cam-type deformity, and then it is resected with a $5-\mathrm{mm}$ motorized burr, controlling the amount of resected bone, in lateral position, with fluoroscopy and with the so-called dynamic tests, which objectify the persistence or disappearance of the femoroacetabular impingement during bone resection. Portal exchange is mandatory to be able to visualize and reach the different areas of the femoral neck, preserving the lateral entry point of the retinacular vessels ${ }^{13}$.

The patients were admitted for 24 hours, and a rehabilitation protocol was followed, prioritizing early mobility and walking ${ }^{14}$. In addition, surgical time and surgery-related complications were recorded. The last follow-up update was through a personal interview or telephone contact, determining those patients who required THA or at least had an indication for it (taking these cases as failure of joint preservation). We could get from all the patients new X-rays at last follow up in order to analyze radiological progression of degenerative changes through a comparison with preoperative images. Those patients with joint progressive space narrowing, osteophyte development or appearance of subchondral cysts were considered as a positive radiological progression.

To evaluate the clinical outcomes the Spanish version of the WOMAC functional scale ${ }^{15}$ was carried out preoperatively and on the last follow-up, when modified Harris Hip score was applied ${ }^{16}$. Predictive factors for THA requirement were also analyzed (dichotomized preoperative Tonnis grade $0-1$ vs 1-2, age, sex and presence of advanced chondral lesions that required microfractures). A statistical analysis was performed according to parametric test (t-test and ANOVA). P-value $<0.01$ was considered to determine a statistically significant difference. 
Joint preservation after hip arthroscopy in patients with FAI. Prospective analysis with a minimum follow-up of seven years

Table I. Summary of patients' epidemiology and data analyzed.

\begin{tabular}{|c|c|c|c|c|c|c|}
\hline Patients & sex & age & chondral lesion & microfractures & preoperative Tonnis & THA requirement \\
\hline 1 & 0 & 56 & 0 & no & 2 & Yes \\
\hline 2 & 0 & 23 & 0 & no & 0 & No \\
\hline 3 & 0 & 32 & II & no & 2 & Yes \\
\hline 4 & 1 & 43 & 0 & no & 1 & No \\
\hline 5 & 1 & 32 & II & yes & 3 & No \\
\hline 6 & 1 & 31 & 0 & no & 2 & No \\
\hline 7 & 0 & 46 & 0 & no & 2 & Yes \\
\hline 8 & 1 & 39 & I & no & 1 & No \\
\hline 9 & 1 & 51 & I & no & 1 & No \\
\hline 10 & 1 & 45 & 0 & no & 3 & Yes \\
\hline 11 & 1 & 26 & 0 & no & 1 & No \\
\hline 12 & 1 & 45 & 0 & no & 3 & No \\
\hline 13 & 1 & 39 & 0 & no & 2 & No \\
\hline 14 & 1 & 30 & III & yes & 1 & No \\
\hline 15 & 1 & 38 & 0 & no & 1 & No \\
\hline 16 & 0 & 52 & 0 & no & 0 & No \\
\hline 17 & 1 & 39 & 0 & no & 2 & No \\
\hline 18 & 0 & 44 & IV & yes & 1 & No \\
\hline 19 & 1 & 38 & III & yes & 2 & Yes \\
\hline 20 & 1 & 50 & IV & yes & 3 & Yes \\
\hline 21 & 1 & 35 & 0 & no & 1 & No \\
\hline 22 & 0 & 30 & 0 & no & 1 & No \\
\hline 23 & 1 & 29 & 0 & no & 1 & No \\
\hline 24 & 0 & 33 & 0 & no & 0 & No \\
\hline 25 & 1 & 41 & 0 & no & 1 & No \\
\hline 26 & 0 & 27 & 0 & no & 1 & No \\
\hline 27 & 1 & 42 & 0 & no & 1 & No \\
\hline 28 & 1 & 37 & 0 & no & 2 & No \\
\hline 29 & 0 & 41 & IV & yes & 1 & No \\
\hline 30 & 1 & 36 & 0 & no & 1 & No \\
\hline 31 & 1 & 33 & II & yes & 1 & No \\
\hline 32 & 1 & 43 & III & yes & 1 & No \\
\hline 33 & 0 & 48 & IV & yes & 1 & No \\
\hline 34 & 1 & 23 & II & no & 1 & No \\
\hline 35 & 1 & 30 & II & no & 1 & No \\
\hline 36 & 1 & 38 & 0 & no & 2 & No \\
\hline 37 & 0 & 38 & 0 & no & 1 & No \\
\hline 38 & 1 & 44 & 0 & no & 1 & No \\
\hline 39 & 1 & 31 & 0 & no & 1 & No \\
\hline 40 & 1 & 50 & 0 & no & 2 & Yes \\
\hline 41 & 1 & 32 & 0 & no & 1 & No \\
\hline 42 & 1 & 49 & 0 & no & 2 & No \\
\hline
\end{tabular}




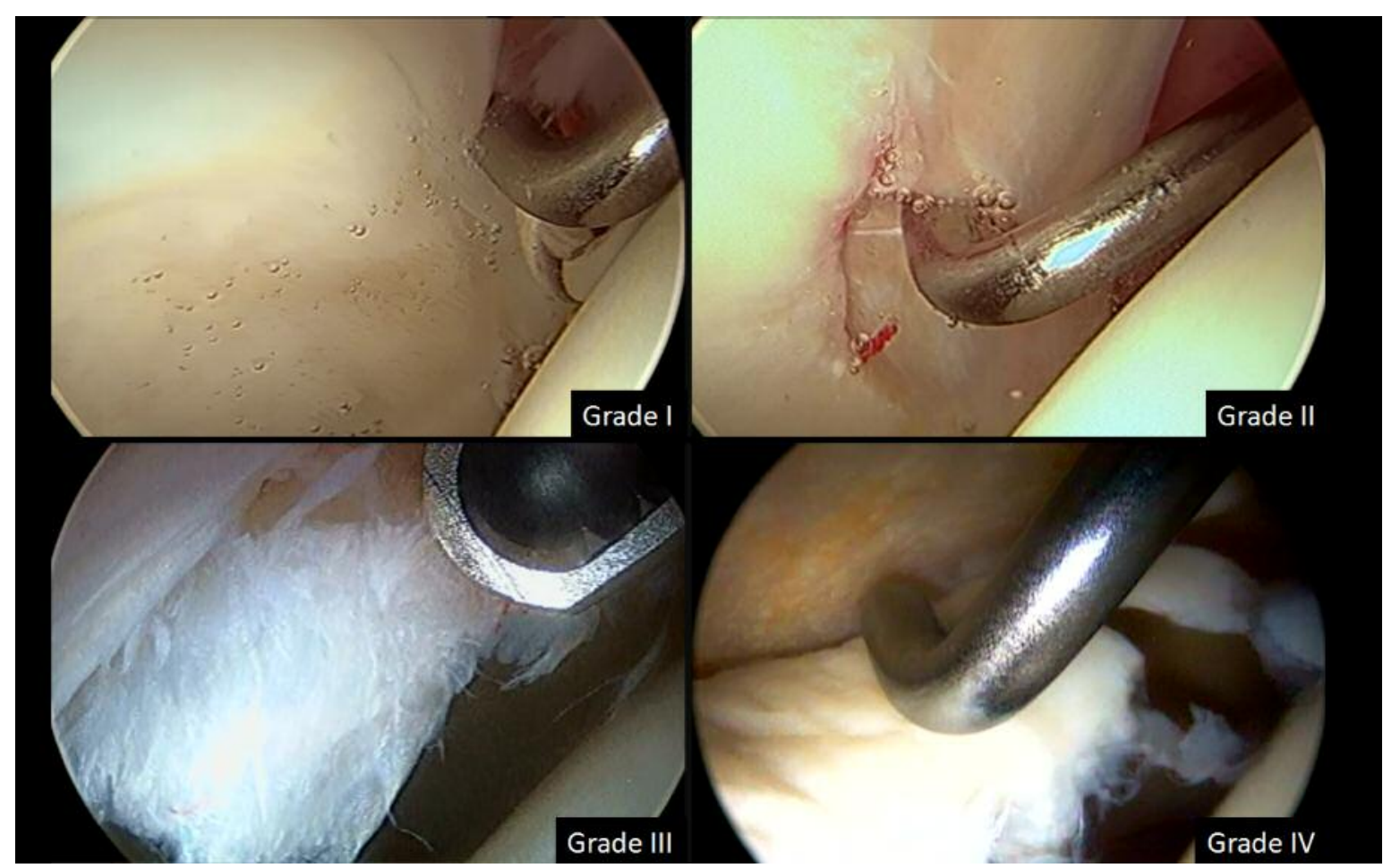

Figure 1. Different types of chondral or chondrolabral lesions according to Outerbridge classification. Grade I: softening, also called wave sign or "wave lesion". Grade II: superficial fissures. Grade III: deep fissures, unstable flaps with no subchondral bone exposure. Grade IV: unstable flap with exposed subchondral bone.

\section{Results}

Prospective follow-up of patients was 91 months on average, with a minimum of 84 months and 97 months maximum. No patients were lost to follow-up. Radiologic analysis of preoperative FAI syndrome type reported 7 cam-type cases (16.6\%), 2 pincertype cases $(4.7 \%)$, and a predominant mixed-type with 33 cases $(78.5 \%)$. Regarding preoperative arthrosis, according to Tonnis scale, 3 patients showed grade $0 ; 24$ patients, grade I; 11 patients, grade II, and 4 patients, grade III, in whom mechanical symptoms were predominant.

Seven of the 42 patients required a total hip arthroplasty at last follow up. Time between hip arthroscopy and THA was an average of 33 months (range 3 to 71 months). Joint preservation rate was $83,3 \%$ (CI95\% $68,64 \%-93,03 \%)$. Analyzing the variables that might have been related to the progression of arthrosis and the consequent THA requirement, we found that in those patients with a radiographic preoperative Tonnis scale 0 and I, the risk was $0 \%$ (CI95\%: 0-12,77), while the probability to evolve to THA in those patients with preoperative Tonnis stages II and III was 46,67\% (CI95\%:21.27\%-73,41\%). There was a statistically significant difference between both groups $(p=0.003)$. Age of 45 years or more at the time of arthroscopy was a significant risk factor to evolve to THA $(p=0.005)$. We did not find a statistically significant association for variables of sex and chondral lesions treated with microfracture (Table II).

Radiological progression of degenerative changes was present in the seven patients who underwent THA (Figure 2). But in those patients who did not require a THA, radiographic analysis addressed a $14,29 \%$ (IC95\% 4,81\%-30,26\%) of progressive degenerative changes without affecting clinical results at last follow up (Figure 3).

Preoperative WOMAC scale score was 77.8 points on average (range 60-80). Excluding those patients who

Table II. Comparison of independent risk factors for THA requirement.

\begin{tabular}{ll}
\hline Men $v s$ Women & $p=0,68$ \\
Age $>=45$ years-old & $p=0,005$ \\
Presence or not of advanced osteochondral lesions treated with microfractures & $p=0,64$ \\
Tonnis preoperative grade: 0 -I vs II-III & $p=0,003$ \\
\hline
\end{tabular}




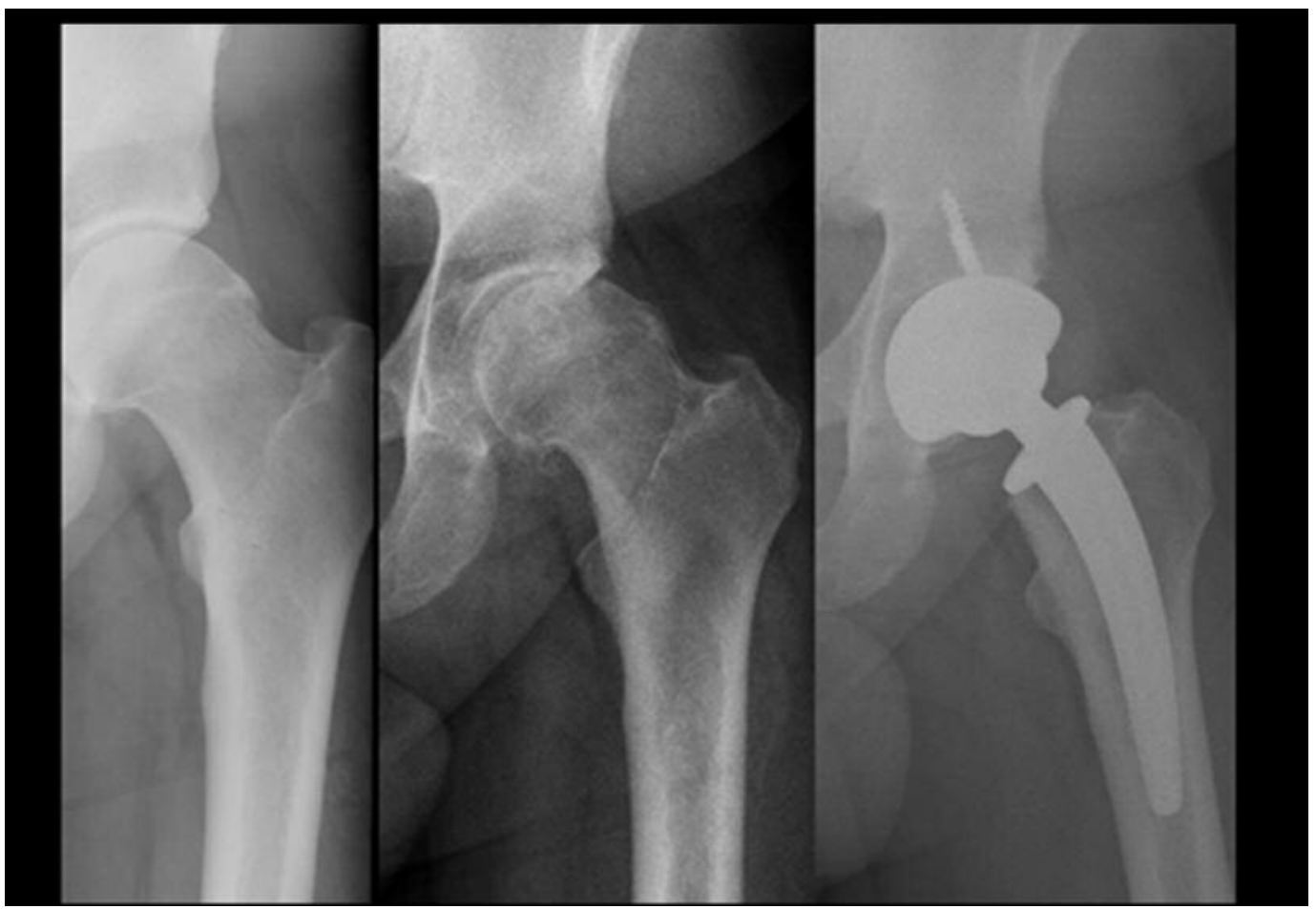

Figure 2. AP left hip X-rays of a patient who presented a radiological degenerative changes progression consistent with clinical failure and the need of a THA after six years of hip arthroscopy (from left to right: preoperative, last follow up and postoperative X-ray with the THA).

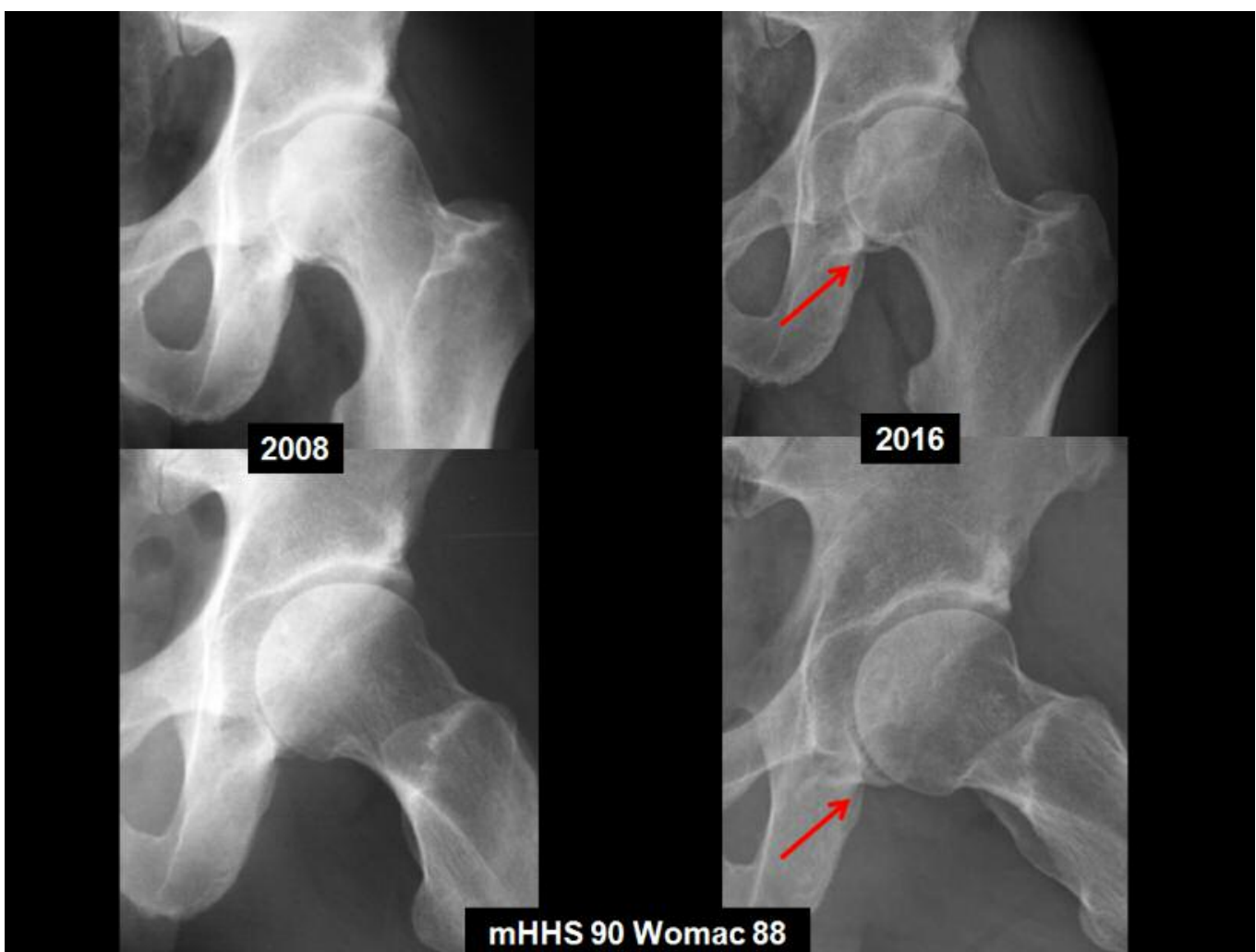

Figure 3. AP left hip X-rays of a patient who presented radiological degenerative changes progression especially in the medial aspect of the joint (arrows) without affecting clinical results at eight years of follow up. 
required THA at last follow up, at final follow-up WOMAC score was 88.6 (range $80-90$ ), and modified Harris score was 88.25 on average (range $80-96$ ). All 42 patients presented with some degree of anterosuperior labral lesion at the time of arthroscopy of the central compartment. We also found, in all cases, sublabral cartilage or chondrolabral lesions. We found exposed subchondral bone (grade IV lesions) in 4 patients, and cartilage delamination with unstable fragments in 11 patients. As mentioned above, labral and unstable chondral lesions were partially resected with shaver and radiofrequency, producing microfractures in the exposed subchondral bone in 9 patients. The rest of the patients presented with lower grades of cartilage lesion (grades I and II).

Average surgical time was 122 minutes (minimum 40, maximum 240).

Regarding complications caused by traction: one male patient $(2.38 \%)$ developed neuropraxia of the pudendal nerve with perineal hypoesthesia and erectile dysfunction, with total recovery by the 5th postoperative day. No other complication was reported.

\section{Discussion}

In our series, hip arthroscopy seems to be an effective and safe treatment for $\mathrm{FAI}$, with an $83 \%$ of good outcome at 7 years follow-up. Tonnis grade II or III osteoarthrosis, and age of 45 years or over are related to a higher risk of THA.

Functional assessment of the patients' preserved joint was positive, with an average postoperative WOMAC score of 88.6 points, and $88.25 \mathrm{mHHS}$ points during the same follow-up period. We also found a $14 \%$ of radiological progressive degenerative changes without affecting clinical results in those patients with successfully joint preservation arthroscopy while the radiological progression consistent with clinical failure was present in all the patients who required a THA.

To our knowledge, few articles reporting clinical outcomes and joint preservation rate with a follow-up longer than 7 years are available in literature. The aim of our study is not to compare open surgery vs hip arthroscopy technique. However, clinical studies regarding hip joint preservation with longer follow reported in literature are about open surgery. Byrd et al. ${ }^{17}$ published the experience with the longest followup, which involved a decade of experience with hip arthroscopy. They evaluated a series of 50 patients (52 hips) who underwent hip arthroscopy for various indications before the concept of FAI syndrome. Conversion rate to THA was $27 \%$ and, as in our series, the grade of preoperative arthrosis was found to be a determining factor for poor prognosis and joint preservation failure ${ }^{17}$. Beck et al. ${ }^{3}$, reported their results of the treatment with safe or controlled hip dislocation in 18 patients with an average age of 38 years and a follow-up period of 4.7 years, finding that 13 of them improved their function and 5 required total hip arthroplasty (28\%).
Murphy et al. ${ }^{18}$ also reported the results of the open treatment of FAl syndrome with an average follow-up of 5 years and 2 months in 23 patients, 7 of whom required THA (30\%). The advanced degree of arthrosis and instability were reported as risk factors. In a recent publication Hufeland et al. analyzed a series of 50 patients treated with hip arthroscopy for FAl. They reported favorable results with a $10 \%$ of conversion to THA at $66.3 \pm 14.5$ months and $12 \%$ of the patients lost to final follow up. They concluded that indication for surgery should be established cautiously when degenerative changes are present and in those patients older than 49 years old ${ }^{19}$.

If we analyze those patients in our series that required THA, we observed that the average period for the second surgery was shorter than 18 months post arthroscopy in five of the seven patients who underwent a THA. This short follow-up until replacement is more closely related to a wrong initial indication in patients with advanced degree of preoperative arthritis than in patients initially benefited from the procedure in which arthritis then progressed over time. The latter occurred only in two patients where THA was indicated after six years of hip arthroscopy. We recently performed a systematic review of the literature about the role of hip arthroscopy in the presence of early osteoarthritis. Although we have found that there is some postoperative clinical outcome improvement of pain and function in a short-term evaluation, increasingly worse outcomes where seen as the severity of $\mathrm{OA}$ increased. At the present we found that level of evidence is low to support the indication a hip arthroscopy in the presence of advanced preoperative osteoarthritis ${ }^{20}$.

Labral and chondrolabral lesions were the most frequent intraoperative findings in our series. Arthroscopic debridement can be associated in these patients with a good clinical result in terms of pain and even more if bone deformities associated to FAI syndrome are also corrected ${ }^{5,17}$. However, poor results have been reported related to labral debridement, mainly in the presence of arthritis ${ }^{17,21}$. Better results have been reported after labral repair, both with open and arthroscopic techniques, suggesting the importance of the labrum to improve joint seal and stability 22,23 . It remains uncertain if labral repair lead to a higher joint preservation rate in the long term but initial results are encouraging.

Functional assessment of patients with FAI syndrome has been performed with different functional scales. Although there is no consensus regarding which is the most suitable scale to assess these patients, WOMAC was used in the present study, since it is the only one validated in Spanish, and modified Harris score mainly as an assessment tool in hip arthroscopy studies, in which it has also been proven useful 24 . This last scale was applied in the last follow-up period, but we did not use it as a preoperative tool in 2008.

The main limitation in the present study is the absence of postoperative radiographic analysis to objectivize the degree of correction of the associated 
bone deformities. Besides, the study is lacking a control group comparing the evolution of arthritis with a different therapeutic approach. Moreover, even though this is a consecutive series, in which patients were followed up prospectively, some of the data were retrospectively documented for this study.

\section{Conclusion}

Based on our own experience, we can affirm that arthroscopic treatment of patients with FAl syndrome leads to favorable results, with a $83 \%$ joint preservation rate at a minimum 7 year follow-up. Patients with advanced preoperatory osteoarthrosis, and patients older than 45 years have a higher risk of requiring THA. This last factor calls for a thorough diagnosis and selection of the surgical candidate in relation to genuine expectations of the procedure in terms of joint preservation.

\section{References}

1. Ganz R, Parvizi J, Beck M, Leunig M, Notzli H, Siebenrock KA. Femoroacetabular impingement: a cause for osteoarthritis of the hip. Clin Orthop Relat Res. 2003:112-120.

2. Beck M, Kalhor M, Leunig M, Ganz R. Hip morphology influences the pattern of damage to the acetabular cartilage: femoroacetabular impingement as a cause of early osteoarthritis of the hip. J Bone Joint Surg Br. 2005;87:10121018.

3. Beck M, Leunig M, Parvizi J, Boutier V, Wyss D, Ganz R. Anterior femoroacetabular impingement: part II. Midterm results of surgical treatment. Clin Orthop Relat Res. 2004:67-73.

4. Lavigne M, Parvizi J, Beck M, Siebenrock KA, Ganz R, Leunig M. Anterior femoroacetabular impingement: part I. Techniques of joint preserving surgery. Clin Orthop Relat Res. 2004:61-66.

5. Clohisy JC, St John LC, Schutz AL. Surgical treatment of femoroacetabular impingement: a systematic review of the literature. Clin Orthop Relat Res. 2010;468:555-564.

6. Leunig M, Ganz R. The evolution and concepts of joint-preserving surgery of the hip. Bone Joint J. 2014;96-B:5-18.

7. Padulo J, Oliva F, Frizziero A, Maffulli N. Muscles, Ligaments and Tendons Journal. Basic principles and recommendations in clinical and field Science Research: 2016 Update. MLTJ. 2016;6(1):1-5.

8. Konan S, Rhee SJ, Haddad FS. Hip arthroscopy: analysis of a single surgeon's learning experience. J Bone Joint Surg Am. 2011;93;2:52-56.
9. Notzli HP, Wyss TF, Stoecklin CH, Schmid MR, Treiber K, Hodler J. The contour of the femoral head-neck junction as a predictor for the risk of anterior impingement. J Bone Joint Surg Br. 2002;84:556-560.

10. Tonnis D, Heinecke A. Acetabular and femoral anteversion: relationship with osteoarthritis of the hip. J Bone Joint Surg Am. 1999;81:1747-1770.

11. Byrd JW. Hip arthroscopy utilizing the supine position. Arthroscopy. 1994;10:275-280.

12. Cameron ML, Briggs KK, Steadman JR. Reproducibility and reliability of the outerbridge classification for grading chondral lesions of the knee arthroscopically. Am J Sports Med. 2003;31:83-86.

13. Byrd JW, Jones KS. Arthroscopic femoroplasty in the management of cam-type femoroacetabular impingement. Clin Orthop Relat Res. 2009;467:739-746.

14. Stalzer S, Wahoff M, Scanlan M. Rehabilitation following hip arthroscopy. Clin Sports Med. 2006;25:337-357, x.

15. Escobar A, Quintana JM, Bilbao A, Azkarate J, Guenaga Jl. Validation of the Spanish version of the WOMAC questionnaire for patients with hip or knee osteoarthritis. Western Ontario and McMaster Universities Osteoarthritis Index. Clin Rheumatol. 2002;21:466-471.

16. Harris WH. Traumatic arthritis of the hip after dislocation and acetabular fractures: treatment by mold arthroplasty. An endresult study using a new method of result evaluation. J Bone Joint Surg Am. 1969;51:737-755.

17. Byrd JW, Jones KS. Prospective analysis of hip arthroscopy with 10-year followup. Clin Orthop Relat Res. 2010;468:741746.

18. Murphy S, Tannast M, Kim YJ, Buly R, Millis MB. Debridement of the adult hip for femoroacetabular impingement: indications and preliminary clinical results. Clin Orthop Relat Res. 2004:178-181.

19. Hufeland M, Krüger D, Haas NP, Perka C, Schröder JH Arthroscopic treatment of femoroacetabular impingement shows persistent clinical improvement in the mid-term. Arch Orthop Trauma Surg. 2016;136(5):687-91.

20. Piuzzi NS, Slullitel PA, Bertona A, Oñativia IJ, Albergo I, Zanotti G, Buttaro MA, Piccaluga F, Comba F. Hip arthroscopy in osteoarthritis: a systematic review of the literature. Hip Int. 2016 Feb 8;26(1):8-14.

21. Farjo LA, Glick JM, Sampson TG. Hip arthroscopy for acetabular labral tears. Arthroscopy. 1999;15:132-137.

22. Espinosa N, Rothenfluh DA, Beck M, Ganz R, Leunig M. Treatment of femoro-acetabular impingement: preliminary results of labral refixation. J Bone Joint Surg Am. 2006;88:925935.

23. Larson CM, Giveans MR. Arthroscopic debridement versus refixation of the acetabularlabrum associated with femoroacetabular impingement. Arthroscopy. 2009;25:369-376.

24. Wright JG, Young NL. A comparison of different indices of responsiveness. J Clin Epidemiol. 1997;50:239-246. 